\title{
Determination of total petroleum hydrocarbons (TPHs) in weathered oil contaminated soil
}

\author{
Meshari Saad Almutairi ${ }^{\dagger}$ \\ Australian collage of Kuwait ACK, Civil Engineering Department, Australian College of Kuwait West Mishref, Safat-13015, Kuwait
}

\begin{abstract}
A new measurement method of weathered crude oil in soil was reviewed. There is no standard method for the extraction of crude oil from soil. Hence, a basic initial test was carried out and several methods such as gravimetric and gas chromatography-mass spectrometry (GC-MS) with various parameters such as weight, solvent and time. The gravimetric process was demonstrated to be the most effective for quantifying weathered contamination crude oil in contaminated soil. The dichloromethane DCM, mixture of DCM: hexane $(1: 1 \mathrm{v} / \mathrm{v}$ mix $)$ and the mixture of acetone: hexane $(1: 1 \mathrm{v} / \mathrm{v} \mathrm{mix})$ were used to investigate the ability of solvent extraction technique for removing weathered crude oil from soil under various extraction conditions. The mixture of acetone: hexane $(1: 1 \mathrm{v} / \mathrm{v}$ mix $)$ was demonstrated to be the most effective in removing total petroleum hydrocarbons (TPH) from contaminated soils. $5 \mathrm{~g}$ and $1 \mathrm{~g}$ weights of oil-contaminated samples were studied to select the best weight depending on contamination level. $1 \mathrm{~g}$ of contaminated soil was cleaned in three cycles whilst the $5 \mathrm{~g}$ of contaminated soil required six cycles. The selected parameters recovered about $97.20 \%$ of the weathered crude oil. These parameters were influenced with character of high efficiency, low cost, low toxicity, and short time.
\end{abstract}

Keywords: Extraction, Solvents, TPH, Weathered crude oil

\section{Introduction}

During the transformation of released oil, various kinds of physical, biological, and chemical changes happen due to releasing oil into the environment. Collectively the processes as mentioned regarding weathering that explains the action while changing the composition, exposure, execution, and toxicity level of extracted oil [1]. The United States Environmental Protection Agency (USEPA) has found that the soil contaminated with petroleum is harmful to the animals and people's health that affect the lungs, kidney, liver, and nervous system. It also causes cancer and various disorders concerning the reproductive system and the immune system [2]. To determine the total content of oil, there are various methods like total organic carbon (TOC), total carbon (TC), total petroleum hydrocarbon (TPH), etc. Based on the environmental sciences division UK [3], ТPH is a frequently utilized gross parameter to quantify the impurity of the environment created by petroleum hydrocarbons compounds (PHC) products like fuels, oils, lubricants, waxes, and others. There are four primary structural forms in which TPH can be categorized, and these are aliphatic, aromatic, resins, and asphaltenes compounds. Based on the molecular structure, aromatic hydrocarbons are classified into two groups. These groups are high molecular weight (HMW) compounds and low molecular weight (LMW) compounds [4]. For determining the TPH level, the base of traditional wet chemistry methods is the "extraction of contaminant from the sample of soil." Various methods like gas chromatography-mass spectrometry (GC-MS) gravimetric calculation calibrated by an EPA calibration standard are used to determine the level of TPH in the extracted solution. Moreover, this study was also designed because of the limited information about the concentration of the constituent of petroleum hydrocarbons in the Kuwait oil sand. A major factor that triggers the contamination in Kuwait is weathered burnt crude oil, which has been exposed to the environment for over the past 30 years, causing most of its volatile substances to evaporate into the atmosphere with heavy compounds left as a residue. The Iraqi military extensively laid landmines in Kuwait oilfields as well as other areas around Kuwait in 1991. Unexploded ordnance (UXO) fired during the conflict were also left which need to be cleared. Because of the difficulty of access, no clearance certificates were issued for the wet oil lake features within the
This is an Open Access article distributed under the terms of the Creative Commons Attribution Non-Commercial License (http://creativecommons.org/licenses/by-nc/3.0/) which permits unrestricted non-commercial use, distribution, and reproduction in any medium, provided the original work is properly cited.

Copyright (C) 2022 Korean Society of Environmental Engineers
Received July 07, 2021 Accepted October 06, 2021

${ }^{\dagger}$ Corresponding author

E-mail: m.almutairi@ack.edu.kw

Tel: +9651828 225

ORCID: 0000-0002-7028-1325 
Table 1. Properties of Weathered Oil Contaminated Sand

\begin{tabular}{lcc}
\hline Origin & Value & Analytical method \\
\hline API gravity $\left({ }^{\circ} \mathrm{C}\right)$ range & $17.31-22.83$ & ASTM D1298 [9]. \\
\hline Specific gravity at $15^{\circ} \mathrm{C}$ & 11.82 & ASTM D7042 [10]. \\
\hline SARA analysis & & \\
Saturates & $40.94 \pm 0.60$ & The separation of weathered crude petroleum into group fractions was \\
Asphaltenes & $17.62 \pm 0.40$ & carried out using column chromatography with selective solvents using \\
Resins & $19.43 \pm 0.20$ & USEPA [11]. \\
Aromatics & $22.02 \pm 0.30$ & ASTM D7169 [12]. \\
\hline Boiling point analysis & NA & \\
\hline
\end{tabular}

oil-contaminated areas. Considering the inability to clear wet oil lakes and the depth of excavation in oil-contaminated dry areas, all areas will be subject to further UXO survey and clearance. In addition, due to shifting sands, all areas will need to be surface swept. Because of this, only a few locations were cleared and approved for sampling, such as south of the Burgan oil field.

The present work aims to evaluate the total petroleum hydrocarbon concentration (TPH) because it can determine a wide range of hundreds of different compounds that are present in crude oil. Furthermore, the reason behind the TPH selection among various other methods is that it is the most relevant method in this case because the core contaminants that are supposed to be analyzed are based on petroleum, which could estimate the oil-pollution level and provides better indication of the pollution-degree extracting from oil.

\section{Materials and Methods}

\subsection{Soil Sampling, Preparation, and Analysis}

Weathered contaminated sand samples from the Burgan oil field in the Kuwait desert (29॰06' $-11^{\prime \prime}$ N, 47॰57'56'E) were collected, between January 2021and March 2021. On the first day of each month, a 3-kg sample of oil contaminated sand was collected. Samples of $100 \mathrm{~g}$ were sealed in sterile sampling bags and were then stored in the fridge at $3^{\circ} \mathrm{C}$ until subsequent analysis. Uncontaminated soil was collected from the desert in the Burgan oil field, the soil was sieved through $2 \mathrm{~mm}$ openings for $2 \mathrm{~min}$ to remove coarse particles. Soil texture for uncontaminated soil was $85 \%$ sand and $15 \%$ silt, as determined by the hydrometer method ASTM D7928 [5]. Uncontaminated soil was classified as loamy sand and had the following properties (dry weight basis): $\mathrm{pH}$ of 7.4 at a ratio 1:1 soil to water [6]. The Uncontaminated soil contained $0.7 \%$ organic matter according to Walkley-Black method [7]. Water saturation for this soil was $23.6 \mathrm{~cm} / \mathrm{h}$ on a dry weight basis, based on ASTM F1815-11 [8]. Weathered oil contaminated sand with properties shown in Table 1 was used for the test.

\subsection{Extraction Process}

At a ratio of $1: 1 \mathrm{w} / \mathrm{w}$, the soil with full of contamination of $1 \mathrm{~g}$ and the mixing of it with Hydromatrix concentrate was employed (Varian, UK). Then to make the appearance of the mixture dry and powdery, it was ground vigorously. The addition of sample in a
$22 \mathrm{~mL}$ stainless steel extraction vial was done (Dionex, UK) and partitioned with disposable cellulose filters (Dionex, 52 UK) and acid-washed sand (VWR, UK). Using Dionex method 324 accelerated solvent extractor (ASE) 200 (Dionex, UK) has been used for the process of extraction. The ASE cell is left in an ASE carousel to facilitate the process of extraction. Hexane/acetone, 1:1 (Fisher Scientific, UK) brought into the cell together with the level up to $50 \mathrm{~mL}$ while extraction takes place. With the assistance of nitrogen, the flushing out of extract from the cell into a collection bottle. To perform the analysis on the extract, GC-MS was used. Then, the specimen solution with the amount of $1.5 \mathrm{~mL}$ was pipetted into the GC autosampler vial (Technopath, UK) and capped by crimp caps.

\subsection{Measuring the Levels of Weathered Crude Oil by GC-MS}

Due to the effectiveness of GC-MS in various major classes of organic samples, it has been employed widely in ongoing research regarding the environment. On a Varian 21-MS IT and a Varian 43GC with an auto-sampler CP-8400 (Fig. 1), analyses of weathered crude oil in terms of TPH were done to observe and assess the soil sample for the traces of petroleum hydrocarbons. For the GC-MS, the assistance of a DB-5 MS capillary column $(15 \mathrm{~m} \times 0.32 \mathrm{~mm}$ i.d. $\times$ $0.1 \mu \mathrm{m}$ film) was employed. The working of the GC-MS is done by mixing the solution of the specimen with air and helium into the column. Here are these conditions for GC-MS; oven temperature program, $50^{\circ} \mathrm{C}$, injector temperature, $300^{\circ} \mathrm{C}$; for $2 \mathrm{~min}-300^{\circ} \mathrm{C}$ for $20 \mathrm{~min}$ at $5^{\circ} \mathrm{C} / \mathrm{min} .1 \mu \mathrm{l} \mathrm{sample}$ of the sample brought together into the GC inlet by injection in this state it vaporised and swept onto a chromatography column by helium, which is used as the carrier with a constant flow rate of $1.0 \mathrm{~mL} / \mathrm{min}$ at $300^{\circ} \mathrm{C}$ and then carried on to the MS console. The electron impact model was used for the ionisation of the sample. The MS was scanned from $\mathrm{m} / \mathrm{z}$ 35-550, with a $3 \mathrm{~min}$ solvent delay and a 150-threshold count.

\subsection{Gravimetric Method for Analysis of Weathered Crude Oil}

There are two phases of the gravimetric method. Phase one focuses on the extraction of the weathered crude oil from sand, whereas the second phase focuses on determining the total petroleum hydrocarbons recovered percentage from contaminated sand. Here is a procedure through which the oil was extracted from the sand. One gram of full of contaminated soil sample was specified by using a screw-capped bottle with the ratio of $(1: 1 \mathrm{v} / \mathrm{v})$ of acetone and hexane solvent and the amount of $5 \mathrm{~mL}$ of this ratio. Then in an ultrasonication bath, it was washed for $5 \mathrm{~min}$. The dry and 
clean weighed round-bottomed glass flask, the crude oil and the acetone: hexane $(1: 1 \mathrm{v} / \mathrm{v})$ solution were pipetted. By using fresh solvent for each cycle, the ultrasonication cycle was then revised four times. The dry weight was noted after the air dry of isolated sand for $2 \mathrm{~h}$. The collection apparatus, distillation head with condenser sidearm, water bath, and conical flask all were arranged and fixed. For the rapid evaporation of the acetone: hexane mix, the temperature of the water bath has been kept at $52^{\circ} \mathrm{C}$. At last, to calculate the isolated weathered crude oil concentration, the weight of crude oil was reweighted when the round glass flask was dried, and the acetone: hexane mix was recovered.

$$
\text { mg Oil/sample } g=\frac{(\mathrm{Wb}-\mathrm{Wa}) \times 1000}{\mathrm{~g} \text { sample }}
$$

Where, the weight of the crude oil sediment plus the round flask is $\mathrm{Wb}$, while the weight of the round flask is Wa. While the percentage removal of weathered crude oil is calculated by

$$
\text { Weathered crude Oil \% }=\frac{\mathrm{Wd}-\mathrm{Wf}}{\mathrm{Wd}} \times 100
$$

Where, the initial concentration of the weathered oil in the soil (g) before washing is $\mathrm{Wd}$, while the concentration of weathered crude oil in the soil (g) after washing is Wf.

\section{Results and Discussion}

\subsection{Analysis of weathered Oil Using Gas Chromatography-Mass Spectrometry (GC-MS)}

In analytical chemistry, all of the extraction procedures mainly aim to separate the analyte from its speedily, quantitatively, and utilising as little solvent as possible [13]. To extract quantitatively several semi-volatiles comprising, phenols, polychlorinated biphenyls (PCBs), Polycyclic Aromatic Hydrocarbons (PAHs) as well as total petroleum hydrocarbons, and accelerated solvent extraction (ASE) procedure was used [14]. The segregation, identification, and quantification of a complex mixture of chemicals, an instrumental method known as GC-MS containing a gas chromatograph (GC) coupled to a mass spectrometer (MS) was used. To examine hundreds of compounds compared to LMW, this method proves one of the most suitable methods. For the analysis using the GC-MS technique, the compound should be thermally stable and satisfactorily volatile. To analyse weathered oil in the soil, this study was done using GS-MS. The initial results indicated that the GC-MS analyses showed that the TPH concentration variation from 183,432 to $212,993 \mathrm{mg} / \mathrm{kg}$ was observed. These results were based on the preliminary study done for the weathered oil contaminated sand. By this analysis, in the sample, no traces of PAH compounds were observed. It was illustrated by the GC profile that after passing $15 \mathrm{~min}$, the level of TPH begins to rise, which shows the fact that the long-chains of hydrocarbons were presented in the sample, Fig. 1.

The sample's chemical modification is necessary to omit all those compounds that can put an influence the quality of obtained record before conducting the GC analysis. To take a correct and precise calculation for aromatic and aliphatic compounds and protect the GC, the high content of asphaltenes was removed. As most of the constituents could not be resolved, the major portion of the diesel oil was also not specified. These constituents appear as 'hump' in the chromatogram, which is named unresolved complex mixture' (UCM), containing branched, cyclic alkanes, and polar transformation products [15]. The resolved hydrocarbons are referred to as 'total resolved hydrocarbons' (TRH). To become TPH, the UCM and TRH were combined. In the GC-MS, the TRH is observed as peaks that are non-degraded hydrocarbons, as Fig. 2 illustrates.

During the measurement, this method faced some difficulties. 'Blocked after each run' was the main challenge caused by the GC column. So, this difficulty gave rise to the need for an alternative way for analysing TPH from samples of soils, as provided in the next passage.

In comparison to the non-weathered samples, the chemical and physical properties of the weathered contaminated soil changed over time, resulting in contaminated soil with a larger oil molecular weight and greater density and viscosity $[15,16]$. It was then assumed that the organics and non-organics (such as sulfur, carbon residues, aromatics, asphaltenes, and metals) in the oil have concentrated more than those in the original oil. By the early 1970s, the term unresolved complex mixture (UCM) was used to describe a broad class of petroleum-based environmental contaminants [16]. This "hump-fit" approach to distinguishing different sources of UCM has been used for over four decades. The method provides little information about the chemical composition of UCM. Additional information is required to accurately determine the source of UCM contamination, determine the extent of UCM weathering or biodegradation, and evaluate the residual toxicity. The most volatile

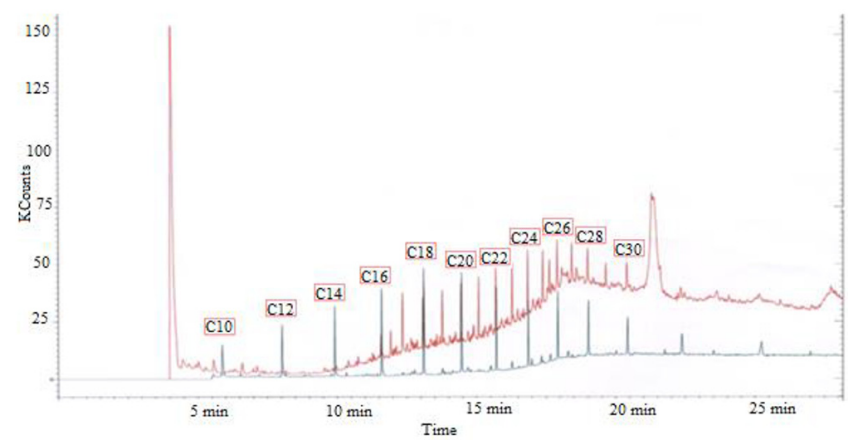

Fig. 1. Chromatograph, with the green label representing the carbon number.

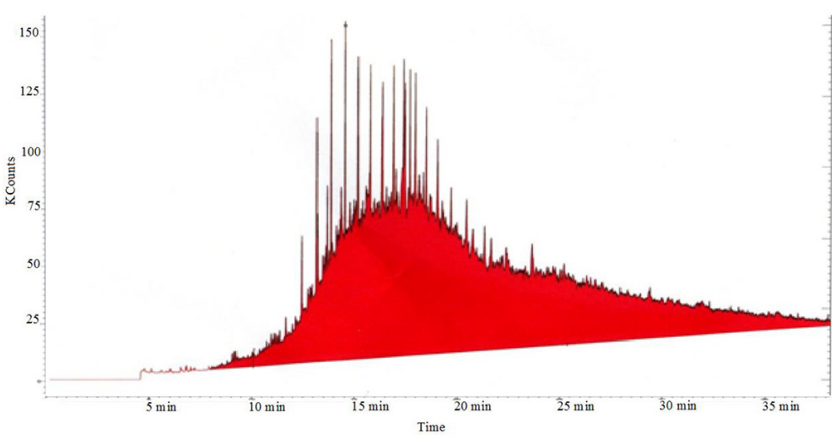

Fig. 2. GC-MS, showing analysis of (UCM) for Kuwait oil sand. 
compounds are removed via evaporation, polar and water-soluble compounds are removed via dissolution, furthermore, biodegradation attacks the linear alkanes, branched alkanes, and then the cycloalkanes and aromatics [17]. This hump is formed by recalcitrant petroleum compounds that do not degrade. A GC-MS study was carried out on weathered and non-weathered soil samples to measure the concentration of these compounds in the sand. Fig. 1 indicates the majority of carbon numbers more than C16 was increased. With the unresolved complex mixture in Fig. 2, the weathered samples reasonably represent real-life contaminated soil. This finding is similar to Urum et al. [18], this may be due to the nature of contamination. Lighter n-alkanes are found in the lowest concentrations. As their molecular weight increases, their concentration increases Fig. 1. The alkane n-C10 is found as a minor constituent with a concentration between $420.5 \mathrm{mg} / \mathrm{kg}$ and $662.8 \mathrm{mg} / \mathrm{kg}$. The concentration of n-C16 and > n-C30 was about $15,700 \mathrm{mg} / \mathrm{kg}$ and $28,800 \mathrm{mg} / \mathrm{kg}$, respectively. Such a characteristic is typical of hydrocarbons of natural origin, such as oil spills [19]. Diesel n-alkane peaks are seen in the chromatogram since the peaks were preferentially extracted from sand using combinations of solvents. The shape and range of this hump are almost identical to those observed by Reddy at the same site 19 years earlier (see Fig. 2) [20]. The peaks visible on top of the UCM may be caused by other abundant contaminants such as polycyclic aromatic hydrocarbons (PAHs), polychlorinated biphenyls (PCBs), and substituted benzotriazoles [21, 22]. Numerous PAHs were also identified in this sample, and they form a band across the GC-MS chromatogram from phenanthrene (peak 4) to benzo[ghi]perylene (peak 12).

\subsection{Analysis of Weathered Crude Oil Using Gravimetric Method}

For the distinction of TPH in impure soil with petroleum hydrocarbon products, there is no standard method yet available [23]. For this purpose, various researches [24, 25] have been conducted and utilized. ASE, Soxhlet extraction, or ultrasonication was involved in most of the techniques that were used for the separation of oil from the sand in the laboratory. With the help of a suitable solvent, ultrasonication has been chosen for the extraction of the oil from the contaminated sand. It is conveniently available with high extraction efficiency and is economical. Using the gravimetric technique, the amount of weathered crude oil can be calculated.

\subsubsection{Different sample weight}

Beginning from the most polluted sample, the selection of $5 \mathrm{~g}$ and $1 \mathrm{~g}$ of the oil contaminated samples was based on the level of contamination present in them. Three cycles were required to clean out $1 \mathrm{~g}$ contaminated soil, while six cycles were needed to clean $5 \mathrm{~g}$ contaminated soil. After completing the washing cycle and extraction, the weight of crude oil and the weight of the oil-contaminated soil sample were calculated through equation 1. Moreover, the data is given in Table 2.

With $15 \mathrm{~mL}$ of the solvent, the one gram of sample took 30 min to clean, while with $150 \mathrm{~mL}$ of solvent, the $5 \mathrm{~g}$ sample took $60 \mathrm{~min}$ to clean. By gradually increasing the weight of the sample soil, the compatibility of the oil contaminants and extraction of solvent was not likely to be altered. So that is why in this study, $1 \mathrm{~g}$ was recommended.

\subsubsection{Type of solvent}

To do the process of flushing out of crude oil from contaminated sand in a short time with high extraction efficiency and a less harmful product, this technique involved some 'determining suitable solvents. A wide range of solvents like dichloromethane (DCM), chloroform, and hexane can be used. For the current experiment, DCM, DCM: hexane (1:1 mix), and acetone: hexane (1:1 mix) was the selected solvents. In the isolation of organic compounds from soil, these solvents were found to be the most influential solvent than other solvents [26]. By using the primary method elaborated in Section 2.4, the selected solvents were characterized using the same procedures as employed above and conducted in three trials. Different solvents trials were made, and in three washes, the ultrasonication process cleans out $1 \mathrm{~g}$ of contaminated soil. The sand weight for all 3 samples and processed oil was calculated after completing the solvent recovery process, as presented in Table 3.

Table 2. The Weight and Concentration of Oil Residue in Contaminated Sand $(n=3)$

\begin{tabular}{lccc} 
& Weight of the sample (g) & Weight of the crude oil sediment (g) & Concentration of crude oil (mg/kg) \\
\hline Sample $5 \mathrm{~g}$ & 5.20 & 1.80 & 346,000 \\
Sample $1 \mathrm{~g}$ & 1.00 & 0.33 & 330,000 \\
\hline
\end{tabular}

Table 3. Analysis of the Oil Contaminated Samples and Crude Oil Concentrations

\begin{tabular}{ccccc}
\hline & & Weight of the sample (g) & Weight of the crude oil sediment (g) & Concentration of oil residue (mg/kg) \\
\hline \multirow{2}{*}{ Sample + DCM } & Trial 1 & 1.21 & 0.33 & 272,000 \\
& Trial 2 & 1.10 & 0.27 & 245,000 \\
& Trial 3 & 1.20 & 0.31 & 258,000 \\
\hline Sample + & Trial 1 & 1.09 & 0.35 & 321,000 \\
DCM: Hexane & Trial 2 & 1.22 & 0.39 & 320,000 \\
(1:1mix) & Trial 3 & 1.23 & 0.37 & 301,000 \\
\hline Sample + & Trial 1 & 1.00 & 0.34 & 340,000 \\
Acetone: Hexane & Trial 2 & 1.08 & 0.37 & 343,000 \\
(1:1mix) & Trial 3 & 1.23 & 0.42 & 341,000 \\
\hline
\end{tabular}


Based on Table 3, for the solvent ratio of acetone: hexane (1:1 $\mathrm{v} / \mathrm{v}$ ), the highest concentration of the crude oil on average was $341,000 \mathrm{mg} / \mathrm{kg}$. As chloroform affects the central nervous system and the people who have experienced exposure to a certain amount of chloroform turned unconscious, so it isn't suggested in this study. The ratio of acetone: hexane has high efficiency of extraction because of its dependence on the mixture solvent polarity for removing oil contaminants. Additionally, to extract petroleum products from the soil, many authors have used them [27-30]. The mixture of acetone: hexane $(1: 1 \mathrm{v} / \mathrm{v})$ was revealed by this experiment to be the suitable solvent system of choice for extracting oil from impure sand.

\subsubsection{Different ultrasonication cycles}

To explore the fact that whether a decrement of the cycle optimised, the process of extraction was the main aim behind the use of various ultrasonication cycles. Three cycles and each cycle based on $10 \mathrm{~min}$ were required for the $5 \mathrm{~mL}$ of acetone: hexane (1:1 $\mathrm{v} / \mathrm{v}$ ) in the previous experiments (Section 3.2.2). A comparison was then made between the results of this experiment with an alternative experiment that needed four cycles. Each cycle was based on the short time of $5 \mathrm{~min}$ for cleaning the $1 \mathrm{~g}$ of soil sample using $5 \mathrm{~mL}$ of the ratio of acetone: hexane (1:1 v/v) solvent. So, a total volume of $20 \mathrm{~mL}$ of solvent was the basic need to complete the process of extraction as the test shows that the 4 cycles were necessary if the washing of sample was done with the rate of $5 \mathrm{~min} /$ cycle. So $30 \mathrm{~mL}$ of solvent was needed for the entire process as the washing of samples required three cycles, and each cycle is based on $10 \mathrm{~min}$, and the results are shown in Fig. 3.

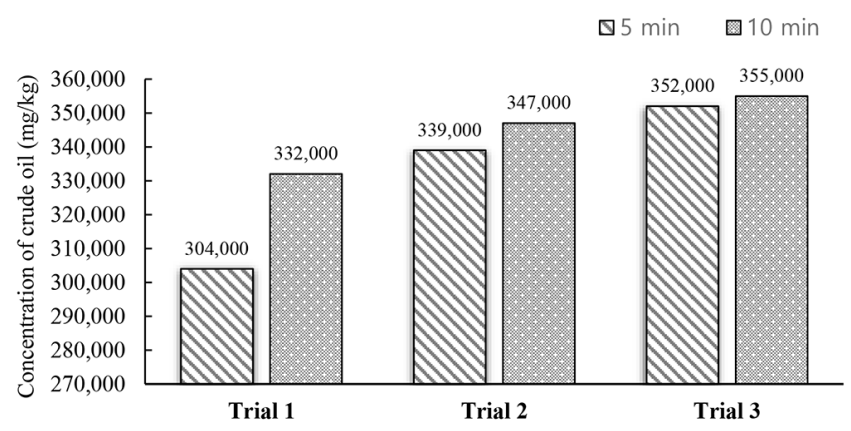

Fig. 3. The concentration of oil residue after $5 \mathrm{~min}$ and $10 \mathrm{~min}(\mathrm{n}=3)$.
Regardless of the washing cycle time, no significant distinctions in weathered crude oil's concentration were observed, based on Fig. 3. The mean values for 5 and $10 \mathrm{~min}$ were calculated as 344,000 and 331,000, respectively (Post-hoc Scheffe test, $P<0.05$ ) showed by the results. Three cycles, $15 \mathrm{~mL}$ of solvent, and $10 \mathrm{~min} /$ cycle for washing 2 samples per hour were required by the previous experiment (Section 3.2.2). More solvent with less time was used by the alternative experiment. So, the washing of three samples can be done in $60 \mathrm{~min}$. Hence, the result recommended the choice of the 5-min cycle over a 10-min cycle.

\subsubsection{Validation of the gravimetric method}

In $5 \mathrm{~mL}$ fresh crude oil, one gram of clean sand was mixed. In four wash cycles (Section 2.4) the combination of crude and sand oil was washed with the solvents of amount of $20 \mathrm{~mL}$ in 20 minutes. The weight of sand and recovered oil was calculated after completing the solvent recovery process, as shown in Table 3. The previous experiment (Section 2.4) recovery of the crude oil was about $97.20 \%$, as shown by the results of Table 4 .

Solvent extraction has also been investigated for treating soils contaminated with hydrocarbons in the diesel range using mixed solvents ethyl acetate-acetone-water and mixed solvents acetonehexane [31, 32]. Based upon the outcomes of their study, acetone and hexane were considered as promising solvent extraction for removing heavy oil fractions as well as petroleum hydrocarbons from contaminated soils. The objective of the present work is to propose substitution solvent for the extraction of hydrocarbons compounds from soil. Furthermore, this study proposed that four principal characteristics influence the choice of method to recover the crude oil: (1) Reduction of the cost of the extracting solvent by decreasing the quantity of solvent (2) the solvent should dissolve the crude oil in the shortest time (3) high extraction efficiency and (4) select the solvent that has the least side effect. In this research, the volatility of the selected solvents was already high, so the temperature of the extraction was not examined. The most important physicochemical parameters in the choice of an appropriate solvent for hydrocarbons compounds extraction were reviewed and selected based on their hazard characteristics. This study found that the extraction efficiency of acetone: hexane (1:1 v/v mix) was higher than those obtained with dichloromethane DCM or

Table 4. Analysis of the Oil Contaminated Samples and Crude Oil Concentrations

\begin{tabular}{|c|c|c|c|c|c|c|}
\hline & Trial (1) & Trial (2) & Trial (3) & Trial (4) & Trial (5) & Trial (6) \\
\hline Weight of sand (g) & 10.0 & 10.07 & 10.09 & 10.03 & 10.02 & 10.03 \\
\hline Volume of fresh crude oil (mL) & 5.00 & 5.00 & 5.00 & 5.00 & 5.00 & 5.00 \\
\hline Weight of vial (g) & 13.51 & 13.53 & 13.44 & 13.20 & 13.45 & 13.30 \\
\hline Weight of vial + sand + crude oil $(g)$ & 28.51 & 28.60 & 28.53 & 28.23 & 28.47 & 28.33 \\
\hline Weight of round bottom flask (g) & 110.20 & 105.40 & 110.98 & 111.13 & 110.94 & 108.30 \\
\hline Weight of crude oil + round bottom flask after separation (g) & 115.00 & 110.30 & 115.77 & 116.00 & 115.88 & 113.17 \\
\hline Volume of crude oil after separation (mL) & 4.80 & 4.90 & 4.79 & 4.87 & 4.94 & 4.87 \\
\hline Weight of vial \& sand after separation (g) & 23.31 & 23.57 & 23.49 & 23.22 & 22.85 & 23.10 \\
\hline Weight of sand after separation (g) & 9.80 & 10.04 & 10.05 & 10.02 & 9.40 & 9.80 \\
\hline Percentage of the recovered oil (\%) & 96.00 & 98.00 & 95.80 & 97.40 & 98.80 & 97.40 \\
\hline
\end{tabular}


mixture of DCM:hexane (1:1 v/v mix). The reason for this might be the nature of the weathered oil contamination.

\section{Conclusions}

During the measurements, some difficulties were faced by this study. 'Blocked after each run' was the main problem faced due to the GC column. Hence there was a need for another way for the TPH examination in impure soil. While the extraction of weathered oil from contaminated soils, the mixtures of (acetone: hexane $\mathrm{v} / \mathrm{v}$ ) in a mixed solvent were effective. This experiment indicates that by increasing the soil sample's weight or the contact time, the compatibility of the solvent extraction and contaminants of oil were unlikely to be altered. For the extraction of three samples in 60 min the developed gravimetrical method used more than one solvent in a short span. Limited locations in the Kuwait oil field were cleared and approved, therefore, the developed extraction process needs to be repeated for other locations once it's become clear to validate the accuracy of the extraction process.

\section{Acknowledgments}

The author gratefully acknowledges the support of the Ministry of Higher Education, Kuwait, for providing the Ph.D. scholarship, which helped the successful accomplishment of this research. Special thanks are also due to the staff of the Civil Engineering Department at University of Portsmouth for support rendered in conducting the laboratory tests required for this research. My deep gratitude to my lovely mother soul for her loving support during this work.

\section{Author Contributions}

M.S (Researcher/Assistant professor) conducted all the experiments and wrote the manuscript.

\section{References}

1. Lehr WJ. Review of modeling procedures for oil spill weathering behavior. Adv. Ecol. Sci. 2010;9:51-90.

2. U.S. Environmental Protection Agency (USEPA). Provisional Peer-Reviewed Toxicity Values for Complex Mixtures of Aliphatic and Aromatic Hydrocarbons. U.S. Environmental Protection Agency, Washington DC; 2009. EPA/690/R-09/059F Final 9-30.

3. Environmental Sciences Division (ESD). Use of Gross Parameters for Assessment of Hydrocarbon Contamination of Soils in Alberta. Oxford: Alberta Environmet; 1993.

4. Khan MAI, Biswas B, Naidu ESR, Megharaj M. Toxicity assessment of fresh and weathered petroleum hydrocarbons in contaminated soil-a review. Chemosphere 2018;212:755-767.

5. ASTM D7928-21e1, Standard Test Method for Particle-Size
Distribution (Gradation) of Fine-Grained Soils Using the Sedimentation (Hydrometer) Analysis, ASTM International, West Conshohocken, PA, 2021.

6. U.S. Environmental Protection Agency (USEPA). Method 9045C: Soil and waste $\mathrm{pH}$. Test methods for evaluating solid waste, physical/chemical methods. EPA Publication. 2003; SW-846, USA.

7. Nelson DW, Sommers LE. Total carbon, organic carbon and organic matter. In: Page, A.L., ed., Methods of Soil Analysis. Part 2. Chemical and microbiological properties. Agronomy Series No. 9, ASA SSSA, Madison; 1982. p. 539-579.

8. American Society for Testing and Materials (ASTM) F1815-1. Standard Test Methods for Saturated Hydraulic Conductivity, Water Retention, Porosity, and Bulk Density of Athletic Field Rootzones, ASTM International, West Conshohocken, PA, 2018.

9. American Society for Testing and Materials (ASTM) D1298-12b. Standard Test Method for Density, Relative Density, or API Gravity of Crude Petroleum and Liquid Petroleum Products by Hydrometer Method; ASTM Int: West Consh, PA, USA, 2017.

10. American Society for Testing and Materials (ASTM) D7042-21. Standard Test Method for Dynamic Viscosity and Density of Liquids by Stabinger Viscometer (and the Calculation of Kinematic Viscosity); ASTM Int: West Consh, PA, USA, 2021.

11. U.S. Environmental Protection Agency (USEPA). Method 8270E (SW-846): Semivolatile Organic Compounds by Gas Chromatography/Mass Spectrometry (GC/MS), Washington, DC, 2014.

12. American Society for Testing and Materials (ASTM) D7169. Standard Test Method for Boiling Point Distribution of Samples with Residues Such as Crude Oils and Atmospheric and Vacuum Residues by High Temperature Gas Chromatography, 2020.

13. Nollet LML, Rathore, HS. Handbook of pesticides: methods of pesticide residues analysis. $1^{\text {st }}$ ed. NW/USA: Taylor \& Francis, CRC press; 2010. p. 257-303.

14. Mantovani CC, Lima MB, Oliveira CD, Menck RA. Diniz EM, Yonamine M. Development and practical application of accelerated solvent extraction for the isolation of cocaine/crack biomarkers in meconium samples. J. Chromatogr. B Analyt. Technol. Biomed. Life Sci. 2014;957:14-23.

15. John WF, James GQ. Unresolved Complex Mixture (UCM): A brief history of the term and moving beyond it. J. Mar. Pollut. Bull. 2015;96:29-31.

16. Farrington JW, Quinn JGJ. Petroleum hydrocarbons in Narragansett Bay. I. Survey of hydrocarbons in sediments and clams (Mercenaria mercenaria). J. Estuar. Coast. Mar. Sci. 1973;1(1):71-79.

17. Volkman JK, Alexander R, Kagi RI, Rowland SJ, Sheppard PN. Biodegradation of aromatic hydrocarbons in crude oils from the Barrow Sub-basin of Western Australia. Org. Geochem. 1984;6:619-632.

18. Urum K, Pekdemir T, Ross D, Grigson S. Crude oil contaminated soil washing in air sparging assisted stirred tank reactor using biosurfactants. Chemosphere 2005;60:334-343.

19. Eglinton G, Hamilton RJ. Leaf epicuticular waxes. Science 1967;156:1322-1335.

20. Reddy CM, Eglinton TI, Hounshell A, et al. The West Falmouth 
oil spill after thirty years: The persistence of petroleum hydrocarbons in marsh sediments. Environ. Sci. Technol. 2002;36: 4754-4760.

21. Latimer JS, Quinn JG. Historical trends and current inputs of hydrophobic organic compounds in an urban estuary: the sedimentary record. Environ. Sci. Technol. 1996;30:623-633.

22. Reddy CM, Quinn JG, King J. Free and Bound Benzotriazoles in Marine and Freshwater Sediments. Environ. Sci. Technol. 2000;34:973-979.

23. U.S. Environmental Protection Agency (USEPA). Toxicological profile for Total Petroleum Hydrocarbons (TPH). Prepared by Research Triangle Institute for the U.S. Department Of Health And Human Services Public Health Service. 1999; 205-93-0606.

24. Villalobos M. Avila-Forcada AP and Gutierrez-Ruiz ME. An improved gravimetric method to determine total petroleum hydrocarbons in contaminated soils. J. Water Air Soil Pollut. 2008;4:151-161.

25. Guy S, Eyal B, Gil E. Quantitative Analysis of Total Petroleum Hydrocarbons in Soils: Comparison between Reflectance Spectroscopy and Solvent Extraction by 3 Certified Laboratories. J. Appl. Environ. Soil. 2012;1:1-11.

26. Osman R, Saim N. Selective Extraction of Organic Contaminants from Soil Using Pressurised Liquid Extraction. J. Chem. 2013;2:1-8.

27. Somasundaran P, Zhang L, Zheng J, Ososkov V, Chou CC. Removal of nonvolatile hydrophobic compounds from soils by flotation I. Laboratory investigation using a mechanically agitated machine. G. Adv. Environ. Res. 1997;2:157-165.

28. Zhang L, Somasundaran P, Ososkov V, Chou CC. Flotation of hydrophobic contaminants from soil. Colloids Surf $A$ Physicochem. Eng. Asp. 2001;77:235-246.

29. Kuk MS, Tetlow R, Dowd MK. Cottonseed extraction with mixtures of acetone and hexane. J. Am. Oil Chem. Soc. 2005;82:609-612.

30. Alena R, Lidmila B, Marie K, et al. Separation of azeotropic mixture acetone + hexane by using polydimethylsiloxane membrane. Sep. Purif. Technol. 2016;170:256-263.

31. Silva A, Delerue-Matos C, Fiuza A. Use of solvent extraction to remediate soils contaminated with hydrocarbons. J. Hazard. Mater. 2005;124:224-229.

32. Xingang L, Yongliang D, Guozhong W, Zhongyuan L, Hong L, Hong S. Solvent extraction for heavy crude oil removal from contaminated soils. Chemosphere 2012;88:245-249. 